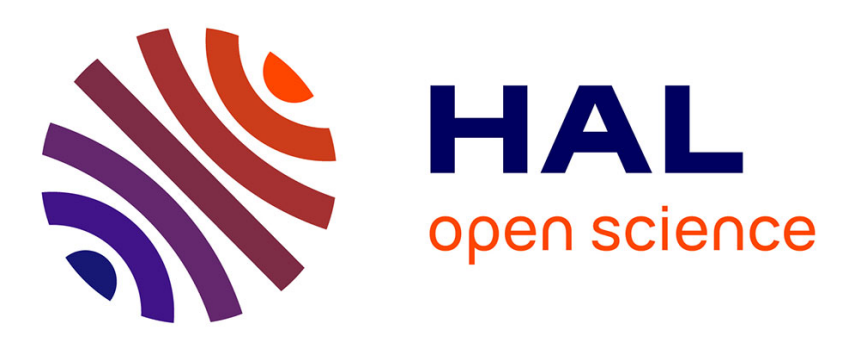

\title{
Meta-population evidence of oriented chain migration in northern gannets (Morus bassanus)
}

Jérôme Fort, Emeline Pettex, Yann Tremblay, Svein-Hakon Lorentsen, Stefan

Garthe, Stephen C. Votier, Jean-Baptiste Pons, Francois Siorat, Robert W.

Furness, W. James Grecian, et al.

\section{To cite this version:}

Jérôme Fort, Emeline Pettex, Yann Tremblay, Svein-Hakon Lorentsen, Stefan Garthe, et al.. Metapopulation evidence of oriented chain migration in northern gannets (Morus bassanus). Frontiers in Ecology and the Environment, 2012, 10 (5), pp.237-242. 10.1890/110194 . hal-01100425

\section{HAL Id: hal-01100425 \\ https://hal.science/hal-01100425}

Submitted on 18 Mar 2015

HAL is a multi-disciplinary open access archive for the deposit and dissemination of scientific research documents, whether they are published or not. The documents may come from teaching and research institutions in France or abroad, or from public or private research centers.
L'archive ouverte pluridisciplinaire HAL, est destinée au dépôt et à la diffusion de documents scientifiques de niveau recherche, publiés ou non, émanant des établissements d'enseignement et de recherche français ou étrangers, des laboratoires publics ou privés. 


\section{Meta-population evidence of oriented chain-migration in northern gannets}

Jérôme Fort ${ }^{1, * \dagger}$, Emeline Pettex ${ }^{2,3, \dagger}$, Yann Tremblay ${ }^{4}$, Svein-Håkon Lorentsen ${ }^{5}$, Stefan Garthe $^{6}$, Stephen Votier ${ }^{7}$, Jean Baptiste Pons ${ }^{2}$, François Siorat ${ }^{8}$, Robert W. Furness ${ }^{9}$, W. James Grecian $^{7}$, Stuart Bearhop ${ }^{10}$, William A. Montevecchi ${ }^{11}$, David Grémillet ${ }^{2,12}$

${ }^{1}$ Department of Bioscience, Aarhus University, Frederiksborgvej 399, 4000 Roskilde, Denmark

${ }^{2}$ Centre d'Ecologie Fonctionnelle et Evolutive, UMR 5175 du CNRS, 1919 route de Mende, 34293 Montpellier cedex 5, France

${ }^{3}$ Centre de Recherches sur les Ecosystèmes d'Altitude, Observatoire du Mont-Blanc, 67 lacets du Belvédère, 74400 Chamonix, France

${ }^{4}$ Institut de Recherche pour le Développement, UMR 212 EME IRD/IFREMER/UM2, Centre de Recherche Halieutique Méditerranéenne et Tropicale, av. Jean Monnet, B.P. 171, 34203 Sète Cedex, France

${ }^{5}$ Norwegian Institute for Nature Research (NINA), NO- 7485 Trondheim, Norway

${ }^{6}$ Research and Technology Centre (FTZ), University of Kiel, Hafentörn 1, 25761 Büsum, Germany

${ }^{7}$ Marine Biology \& Ecology Research Centre, University of Plymouth, Plymouth PL4 8AA, UK

${ }^{8}$ Station LPO de l'Ile Grande, 22560 Pleumeur-Boudou, France 
${ }^{9}$ College of Medical, Veterinary and Life Sciences, Graham Kerr Building, University of Glasgow, Glasgow G12 8QQ, UK

${ }^{10}$ School of Biosciences, University of Exeter, Penryn, Cornwall TR10 9EZ, UK

${ }^{11}$ Cognitive and Behavioural Ecology Program, Memorial University of Newfoundland, St. John's, Newfoundland A1B 3X9, Canada

${ }^{12}$ Percy FitzPatrick Institute, DST/NRF Centre of Excellence, University of Cape Town, Rondebosch 7701, South Africa

*Author for correspondence (fort.jerome@gmail.com; jef@dmu.dk)

${ }^{\dagger}$ These authors contributed equally to this work. 


\section{Summary}

Oriented migrations have been identified in a large number of terrestrial bird species. Conversely, the post-breeding movements of seabirds are generally regarded as dispersive. We used geolocator tags to reveal non-breeding movements and winter distribution of northern gannets (Morus bassanus) at a meta-population scale. By focusing on five major breeding colonies, we show that breeding and wintering grounds of European gannets are connected by a major flyway running along the coasts of Western Europe and Africa. Crucially, maximum winter range was similar across colonies despite their wide latitudinal range. This strongly suggests chain-migration, which contrasts with the general opinion that large pelagic birds such as gannets enjoy unlimited ranges outwith the breeding season. Our study demonstrates oriented migration in gannets, and highlights the benefit of metapopulation approaches for studying seabird movements. It is essential to include such processes in marine management plans due to improve the conservation of marine biodiversity.

Keywords: avian conservation, biotelemetry, non-breeding movements, migration corridor, seabird hotspots, winter distribution 


\section{INTRODUCTION}

Defining animal movements and distribution in space and time is essential for the management and conservation of organisms facing threats from climate change and habitat degradation (Nathan et al. 2008). For instance, determining bird migration routes, and their main wintering quarters, is necessary to identify Important Bird Areas during different periods of their annual cycle. Following analysis of ring-recoveries performed over the last decades, seabird post-breeding movements have generally been considered as dispersive (Wernham et al. 2002; Newton 2008), a conclusion reinforced by their ability to travel thousands of kilometres over very large areas of apparently suitable feeding habitat. This concept has recently been challenged by using miniaturized electronic devices allowing the tracking of seabird migratory movements at different spatio-temporal scales (Ropert-Coudert and Wilson 2005). These biotelemetry studies suggested that migration corridors might occur, even in highly pelagic species (eg Shaffer et al. 2006; Egevang et al. 2010; Stenhouse et al. 2011). This is of conservation relevance, as it suggests that seabird hotspots are not only important during their breeding period, but throughout their entire annual cycle. Most of these investigations were nonetheless based on relatively small sample sizes and/or on single colonies (but see Phillips et al. 2005; González-Solís et al. 2007; Montevecchi et al. 2011). Since different populations are expected to have contrasting migratory behaviours (Newton 2008), it now seems essential to test for oriented seabird migration at a meta-population level in order to identify, at large spatial scales, those sensitive marine areas that might require particular attention and protection.

In this paper, we focus on the northern gannet (Morus bassanus, hereafter 'gannet'), a species widely distributed in the North Atlantic. The biology and foraging distribution of gannets during the breeding season are relatively well understood (Nelson 2002; Pettex et al. 2010; Votier et al. 2010). However, our knowledge of their migratory patterns and winter 
areas remains limited, particularly in the eastern North Atlantic (Montevecchi et al. 2011). Extensive ringing and at-sea surveys helped to identify some staging areas for gannets during the non-breeding period (Barrett 1988; Nelson 2002), though these are limited in scope owing to temporal and spatial biases associated with ring-recovery data. Similarly, ship-based monitoring only allows community-level observations with no information on the origin of individual birds (Tremblay et al. 2009a). Recently, Kubetzki et al. (2009) used geolocators to investigate the migration and wintering areas of individual gannets from a single colony in Scotland, illustrating that individuals used different and rather small over-wintering areas, which is consistent with ring recoveries (Nelson 2002). Our study therefore aims to (1) identify hotspots for different gannet populations during the non-breeding period and (2) test the hypothesis of oriented post-breeding migration in gannets at the meta-population scale.

\section{METHODS}

\section{(a) Study sites and data collection}

We studied the non-breeding distribution of gannets from five European colonies over several years: Storstappen $\left(71^{\circ} 14^{\prime} \mathrm{N}, 2^{\circ} 30^{\prime} \mathrm{E}\right.$; Norway; 2008/2009 - 2009/2010), Store Ulvøyholmen (6851'N, 1451'E; Norway; 2008/2009 - 2009/2010), Bass Rock (5604'N, 2³8'W; Scotland, UK; 2002/2003 - 2003/2004, (see Kubetzki et al. (2009) for details and previous analyses of

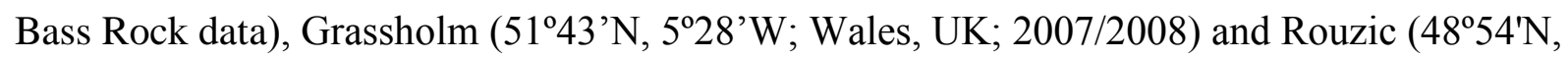
$3^{\circ} 26^{\prime} \mathrm{W}$; France; 2006/2007). These colonies are distributed along a gradient spanning $\sim 23^{\circ}$ of latitude, Storstappen being the northernmost, and Rouzic the southernmost, respectively (see Figure 1 and WebTable 1). Hereafter, and for the sake of simplicity, these 5 colonies are respectively referred to as NO1 and NO2 for the 2 Norwegian colonies, UK1 and UK2 for the 2 UK colonies and FR for the French colony (see Figure 1 and WebTable 1 for details). At each colony, breeding gannets were fitted with a geolocator tag (Global Location Sensor - 
GLS; Wilson et al. 1992 - see WebTable 1 for details). These record time, light levels and temperature throughout the non-breeding period.

Overall, the use of miniaturised GLS allowed us to measure non-breeding movements for 86 gannets from five breeding colonies. For three colonies, birds were equipped over two successive non-breeding periods, revealing high consistency in colony-specific migration patterns (WebFigure 1). Colony-specific data were therefore pooled across years for analyses.

\section{(b) Data analyses}

Light-level data were extracted from GLS and converted into geographic coordinates using two programs: MultiTrace Geolocation (Jensen Software System) for UK1, UK2 and FR data and LAT Viewer Studio (Lotek fish \& wildlife monitoring systems) for NO1 and NO2. Raw spatial positions obtained from these extractions can contain some large errors (Phillips et al. 2004), related to 1) latitude (higher latitudes have constant daylight during summer and constant darkness during winter), 2) the period considered (equal day and night duration during equinoxes), or 3) animal behaviour which might occasionally alter the quality of the light readings. Therefore, and in order to take these errors into consideration, all raw positions were processed using Tremblay et al.'s (2009b) method. The principles of this method are described in detail in the WebPanel 1. The maximum distance to the colony of origin was calculated from the estimated non-breeding positions for the entire period and for each individual. Distances were computed as the great-circle distance on the Earth spheroid, thus taking into account the Earth's curvature but not accounting for land avoidance. These estimates were assumed to represent the distance for each bird between the breeding colony and wintering ground. Values are means \pm s.d.

Kernel analyses were performed in Matlab R2010b (The MathWorks) using $50 \times 50$ $\mathrm{km}$ grid cells to determine the areas preferentially occupied by gannet populations during the 
non-breeding period, also defined as hotspots. Estimation of the kernel bandwidth parameter followed Sheather and Jones (1991). Only cells used by 2 individuals or more were considered, in order to avoid giving importance to areas used by only one individual. Further, the number of locations within one cell was multiplied by the total number of birds contributing to these locations. This transformation favours areas used by many individuals over areas used for a long time by only a few individuals. Gannet hotspots were delimited using $25 \%$ kernel density contours which we considered to be the best representation of coreareas occupied. Kernel analyses were performed during 3 distinct periods defined as 1) prewinter period (1-31 October; when birds were assumed to migrate to their wintering site), 2) winter period (1-31 December; when birds were observed to stay in a restricted area without any large-scale movements) and 3) post-winter period (1-28 February; when birds were assumed to migrate back to their breeding site).

\section{RESULTS}

\section{(a) Ocean basin scale movements}

After their breeding season, almost all gannets moved to the south. Considerable interindividual variability occurred, and birds used an elongated area ranging from the northern North Sea to Northwest Africa. Nevertheless, analyses also revealed colony-specific strategies (Figure 1): during winter, gannets breeding at NO1 were distributed continuously between the North Sea and the northern part of Northwest Africa, with one individual reaching the coasts of the Islamic Republic of Mauritania. Birds from NO2 presented a more restricted and bimodal distribution with most birds remaining in European waters (in the North Sea, the English Channel and the Bay of Biscay), and three other individuals located much further south in northwest African waters and the western Mediterranean. Birds from UK1 showed a 
wide distribution between the North Sea and the Senegal coasts in Northwest Africa. One bird also wintered in the Mediterranean Sea, between Tunisia and Sicily. Similarly to UK1, birds from UK2 were widely distributed between European Seas and northwest Africa. Nevertheless, they mainly remained in the Bay of Biscay, off the west coast of Portugal, and off Northwest Africa. The winter distribution of gannets breeding at FR was also restricted, with almost all birds reaching the northwest African coast, one bird wintering in the Irish Sea while another stayed off the Portuguese coasts (Figure 1). Interestingly, analysis of individual maximum winter distance showed that birds from the different colonies wintered, on average, at similar distances to their colony of origin $(\mathrm{NO} 1=3872 \pm 980, \mathrm{NO} 2=3290 \pm 1282, \mathrm{UK} 1=$ $3411 \pm 1546, \mathrm{UK} 2=3721 \pm 1114, \mathrm{FR}=2979 \pm 781 \mathrm{~km} ;$ ANOVA, $F_{4,80}=1.30, \mathrm{p}=0.278$ Figure 2).

\section{(b) Non-breeding hotspots}

Pre-winter period

In October, kernel analyses (25\% kernels) revealed gannet hotspots around the UK, with large overlaps between the five study populations (Figure 3a). However, despite this overall common distribution, different pre-winter strategies were observed between and among colonies. Birds from UK2 and FR adopted a similar pre-winter strategy, with birds mainly distributed in the Irish Sea. Conversely, the main distribution of birds from NO2 was located in the southern part of the North Sea. Gannets breeding at UK1 and NO1 adopted very similar distributions in October with, in each case, a distribution divided in 2 main areas, one located in the North Sea overlapping the NO2 distribution, and one located in the Bay of Biscay. Surprisingly, while FR birds wintered well to the south (see below), our analysis showed that they initially moved northward after the breeding season (Figure 3a). 


\section{Winter period}

Gannets clearly adopted two distinct and contrasting winter strategies, split in two main distribution areas: one located in Northern Europe and one off the coasts of Northwest Africa (Figure 3b). Overall, there were again large overlaps between the main winter areas occupied by birds from the five colonies. Nevertheless, smaller spatial-scale segregations also appeared during the winter season, between and among colonies. Norwegian birds (NO1 and NO2) were mainly distributed in the North Sea and the English Channel, with a very similar spatial distribution between these two colonies. Unlike autumn, during winter birds from these colonies were the only ones in the North Sea. French birds (FR) also had a single major distribution during winter, located in Northwest Africa. Conversely, the main distribution of birds from UK colonies was divided between two areas, some birds spending the winter in Northern Europe (Irish Sea, English Channel and Bay of Biscay) while the others wintered in Northwest Africa. Interestingly, in northwest African waters, there was a spatial segregation between birds from France and from the UK (UK1 and UK2). Indeed, the main wintering area of French gannets was located off Morocco, while birds from UK colonies wintered further south, off the Islamic Republic of Mauritania and Senegal (Figure 3b).

\section{Post-winter period}

Kernel analyses revealed a strong heterogeneity in gannet at-sea distributions (25\% kernels) in February, both among and between colonies. There was an important segregation between Norwegian birds and those from France and UK, with the former group generally remaining further north (Figure 3c). Divergent distributions were also observed in western European waters, with birds from FR mainly distributed in the English Channel, birds from UK2 restricted to the Irish Sea and to an area along the north coast of Spain, and birds from UK1 
distributed more widely, mainly in the Bay of Biscay, along the Portuguese coast, in the Mediterranean and off Northwest Africa (Figure 3c).

Overall, despite individual and population differences, our analyses revealed the existence of a gannet flyway from northern Norway to West Africa.

\section{DISCUSSION}

By focusing on five European breeding gannet colonies distributed along a latitudinal gradient of ca. $2500 \mathrm{~km}$ including the species southern- and the northernmost breeding sites in the eastern Atlantic, the present study is one of the first to investigate the non-breeding movements and winter distribution of a seabird species at a meta-population scale (but see Frederiksen et al. 2011, Montevecchi et al. 2011). As hypothesized, our findings suggest that gannet post-breeding movements should not be attributed to dispersive migration or vagrancy, but are instead oriented along a major flyway running along the coasts of Western Europe and Africa, from the North Sea to Senegal. These findings confirm recent studies using GLS suggesting that seabirds can, like their terrestrial relatives, follow migration corridors when moving between their breeding and wintering grounds (Egevang et al. 2010, Stenhouse et al. 2011). The GLS method (sensu Wilson et al. 1992), based on light-level recordings, has been effective for tracking small/medium-sized animals over large time scales, but this method also entails a large error of $100-200 \mathrm{~km}$ which limits its use to the study of wide-scale movements (Phillips et al. 2004). Although we used a refined model taking into account potential biases of the method and including sea-surface temperatures to predict individual positions more accurately (Tremblay et al. 2009b; WebPanel 1), we emphasize that small-scale results should be interpreted with caution. 
Overall, our results support previous descriptions of gannet non-breeding areas from ring recoveries and GLS data (eg Barrett 1988; Nelson 2002). We observed a high variability of winter distribution both at the individual and colony levels. Several studies investigating seabird movements have previously shown that individuals from a single colony can segregate during winter and use different wintering sites (Shaffer et al. 2006; González-Solís et al. 2007). In the case of gannets (Kubetzki et al. 2009), such segregation also exists at a meta-population scale, with two main and distinct wintering areas occupied in the Northern Europe seas and off the coast of Northwest Africa. The latter area is important for several other wintering seabirds (Wernham et al. 2002; Camphuysen and van der Meer 2005; González-Solís et al. 2007). This zone off Northwest Africa features one of the four major oceanic upwelling systems of the world. Extending between $10^{\circ} \mathrm{N}$ and $22^{\circ} \mathrm{N}$ during winter, it holds substantial biomass of pelagic fish available to gannets and other marine predators. Local fisheries also discard large volumes of fishery wastes, which are an important food for some gannets (Camphuysen and van der Meer 2005; Votier et al. 2010). This result also confirms that seabirds from various colonies can target and aggregate in a few highly profitable winter areas (González-Solís et al. 2007; Block et al. 2011). Interestingly, a few tracked individuals adopted alternative strategies and instead wintered along the coasts of Portugal, south of Spain and Tunisia. While these strategies are likely to be marginal, our sample sizes are small (notably at UK2 and FR, see WebTable 1) and further studies are required to understand the importance of these alternative grounds for wintering gannets in the context of the two main hotspots identified here.

Beyond the overall bimodal distribution adopted by the European gannet metapopulation, differences arose between colonies at smaller spatial scales in the main wintering areas (estimated from 25\% kernel analysis). Interestingly, these differences are mainly linked to the respective latitude of each colony, and strongly suggest chain migration (a pattern in 
which populations move evenly south, more northern birds wintering in northernmost grounds, Salomonsen 1955; Newton 2008). Indeed, Norwegian birds breeding at higher latitudes mainly wintered in Northern Europe, birds breeding at intermediate latitudes (UK birds) showed a bimodal winter distribution between Northern Europe and Northwest Africa, and French birds breeding at lower latitudes mainly wintered off Northwest Africa. This pattern differs from the leapfrog migration observed in many terrestrial and water bird species, in which birds that breed at highest latitudes spend the winter at lowest latitudes (Newton 2008). Previous studies demonstrated that seabirds can travel impressive distances to reach their winter sites (eg Egevang et al. 2010), and this is also the case for northern gannets, which are capable of travelling up to $7000 \mathrm{~km}$ from their colony after breeding. Nevertheless, the similarity observed between colonies in average maximum winter range (see Figure 2) suggests that an upper limit to gannet travelling may exist. This is surprising since, in great contrast to passerines migrating over water, gannets can presumably rest and feed en route. While chain migrations have been observed in several terrestrial bird species (see Newton 2008 for examples), this is to our knowledge the first direct evidence of an oriented chainmigration in a seabird species. Evidence of such migratory processes has important implications for the conservation of gannets and other seabirds. First, our findings confirm recent investigations suggesting that seabird hotspots also exist during the non-breeding period, along migration corridors and at their wintering grounds (Egevang et al. 2010, Block et al. 2011). They also highlight that location of winter hotspots could be dictated by the origin of birds, suggesting genetic control and reduced short-term individual adaptation to local habitat degradation (Newton 2008). These are crucial information for studies directly aiming at defining important bird areas at sea and further conservation actions. Second, our results show that studies should not be restricted to populations but should rather address meta-population scales, to gain complete overview of sensitive marine areas that might 
require protection. Third, we pinpoint that gannet hotspots move along their migration routes, and can spread far beyond the limits of national waters. This is essential as it demonstrates that future conservation of the marine avian biodiversity might largely depend on the design of adaptive pelagic protected areas and on the capacity of countries to adopt collaborative management plans. Finally, the bimodal strategy used by UK birds is intriguing and merits further investigations. For instance, it has recently been demonstrated that the breeding performance of black-legged kittiwake (Rissa tridactyla) affects their winter distribution, with individuals experiencing a breeding failure overwintering in different (farther) places from successful breeders (Bogdanova et al. 2011). Such mechanisms might also condition the important inter-individual variability observed in the migratory behaviour of gannets from UK colonies. Identifying carry-over effects (Harrison et al. 2011) in seabird behaviour during the non-breeding period, and identifying its impact on population dynamics therefore appears a major goal for forthcoming studies.

\section{Acknowledgements}

We are grateful to Greg Morgan, Lisa Morgan, Matthew Witt, Nory El Ksaby and Mélanie Le Nuz for their hard work in the field. We thank R.A. Phillips for having provided and analysed two GLSs from British Antarctic Survey. Permission to enter the Norwegian colonies was issued by the County Governors of Nordland and Finmark, while permission to handle the birds was given by the Norwegian Directorate for Nature Management and the Norwegian Animal Research Authority. Fieldwork at Rouzic was performed under permission of the Ministère Français de l'Alimentation, de l'Agriculture et de la Pêche (permit 34369). Sir Hew Hamilton-Dalrymple allowed us to work on the Bass Rock, where fieldwork was permitted by Scottish Natural Heritage and the British Trust for Ornithology (permit A2282), and funded by EU project "DISCBIRD”, contract Q5RS-2001-00839. Fieldwork on Grassholm was 
performed with the permission of RSPB and CCW. The Norwegian part of the study was financed by the Directorate for nature Management and SEAPOP (www.seapop.no). JF is supported by a Marie Curie Intra-European Fellowship within the 7th Framework Programme. 


\section{References}

Barrett RT. 1988. The dispersal and migration of the Gannet Sula bassana from Norwegian colonies. Ringing \& Migration 9: 139-145.

Block BA, Jonsen ID, Jorgensen SJ et al. 2011. Tracking apex marine predator movements in a dynamic ocean. Nature 475: 86-90.

Bogdanova MI, Daunt F, Newell M, et al. 2011. Seasonal interactions in the black-legged kittiwake, Rissa tridactyla: links between breeding performance and winter distribution. Proc R Soc B doi: 10.1098/rspb.2010.2601.

Camphuysen CJ and van der Meer J. 2005. Wintering seabirds in West Africa: foraging hotspots off Western Sahara and Mauritania driven by upwelling and fisheries. African J Mar Sci 27: 427-438.

Egevang C, Stenhouse IJ, Phillips RA, et al. 2010. Tracking of Arctic terns Sterna paradisaea reveals longest animal migration. Proc Natl Acad Sci USA 107: 2078-2081.

Frederiksen F, Moe B, Daunt F, et al. 2011. Multicolony tracking reveals the winter distribution of a pelagic seabird on an ocean basin scale. Diversity Distrib DOI: 10.1111/j.1472-4642.2011.00864.x

González-Solís J, Croxall JP, Oro D, et al. 2007. Trans-equatorial migration and mixing in the wintering areas of a pelagic seabird. Front Ecol Environ 5: 297-301.

Harrison XA, Blount J, Inger R, et al. 2011. Carry-over effects as drivers of fitness differences in animal. J Anim Ecol 80: 4-18.

Kubetzki U, Garthe S, Fifield D, et al. 2009. Individual migratory schedules and wintering areas of northern gannets. Mar Ecol Prog Ser 391: 257-265.

Montevecchi W, Fifield D, Burke C, et al. 2011. Tracking long-distance migration to assess marine pollution impact. Biol Lett doi: 10.1098/rsbl.2011.0880. 
Nathan R, Getz WM, Revilla E, et al. 2008. A movement ecology paradigm for unifying organismal movement research. Proc Natl Acad Sci USA 105: 19052-19059.

Nelson B (Ed). 2002. The Atlantic Gannet, 2nd edn. Norfolk: Fenix Books Ltd.

Newton I (Ed). 2008. The migration ecology of birds. London, Academic Press.

Pettex E, Bonadonna F, Enstipp MR, et al. 2010. Northern gannets anticipate the spatiotemporal occurrence of their prey. J Exp Biol 213: 2365-2371.

Phillips RA, Silk JRD, Croxall JP, et al. 2004. Accuracy of geolocation estimates for flying seabirds. Mar Ecol Prog Ser 266: 265-272.

Phillips RA, Silk JRD, Croxall JP, et al. 2005. Summer distribution and migration of nonbreeding albatrosses: individual consistencies and implications for conservation. Ecology 86: 2386-2396.

Ropert-Coudert Y and Wilson RP. 2005. Trends and perspectives in animal-attached remote sensing. Front Ecol Environ 3: 437-444.

Salomonsen F. 1955. The evolutionary significance of bird migration. Dan Biol Medd 22: 1062.

Shaffer SA, Tremblay Y, Weimerskirch H, et al. 2006. Migratory shearwaters integrate oceanic resources across the Pacific Ocean in an endless summer. Proc Natl Acad Sci USA 103: 12799-12802.

Sheather, S. J. and Jones, M. C. 1991. A reliable data-based bandwidth selection method for kernel density estimation. J R Stat Soc B 53: 683-690.

Stenhouse IJ, Egevang C and Phillips RA. 2011. Trans-equatorial migration, staging sites and wintering area of Sabine's Gulls Larus sabini in the Atlantic Ocean. Ibis doi: 10.1111/j.1474-919X.2011.01180.x

Tremblay Y, Bertrand S, Henry RW, et al. 2009a. Analytical approaches to investigating seabird-environment interactions: a review. Mar Ecol Prog Ser 391: 153-163. 
Tremblay Y, Robinson PW and Costa DP. 2009b. A parsimonious approach to modeling animal movement data. Plos One 4: e4711.

Votier SC, Bearhop S, Witt MJ, et al. 2010. Individual responses of seabirds to commercial fisheries revealed using GPS tracking, stable isotopes and vessel monitoring systems. J Appl Ecol 47: 487-497.

Wernham CV, Toms MP, Marchant JH, et al. (Eds). 2002. The migration atlas: movements of the birds of Britain and Ireland. London: T \& AD Poyser.

Wilson RP, Duchamp JJ, Rees WG, et al. 1992. Estimation of location: global coverage using light intensity. In: Priede IM and Swift SM (Eds). Wildlife telemetry: remote monitoring and tracking of animals. Chichester: Ellis Howard. 


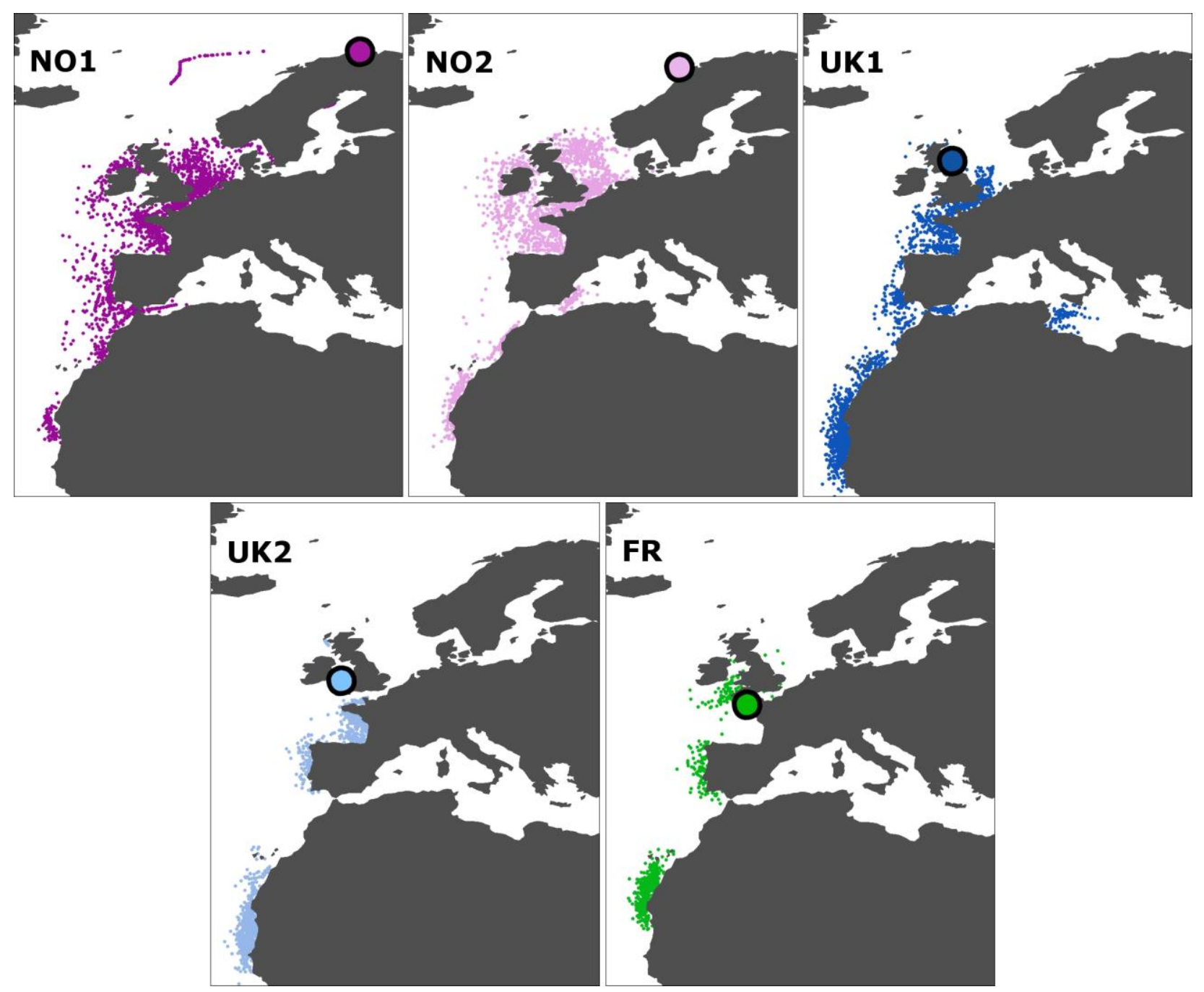

Figure 1. Estimated winter (December) positions for all tracked individuals. On each map, the black-outlined plain-colour dot represents the breeding colony. 


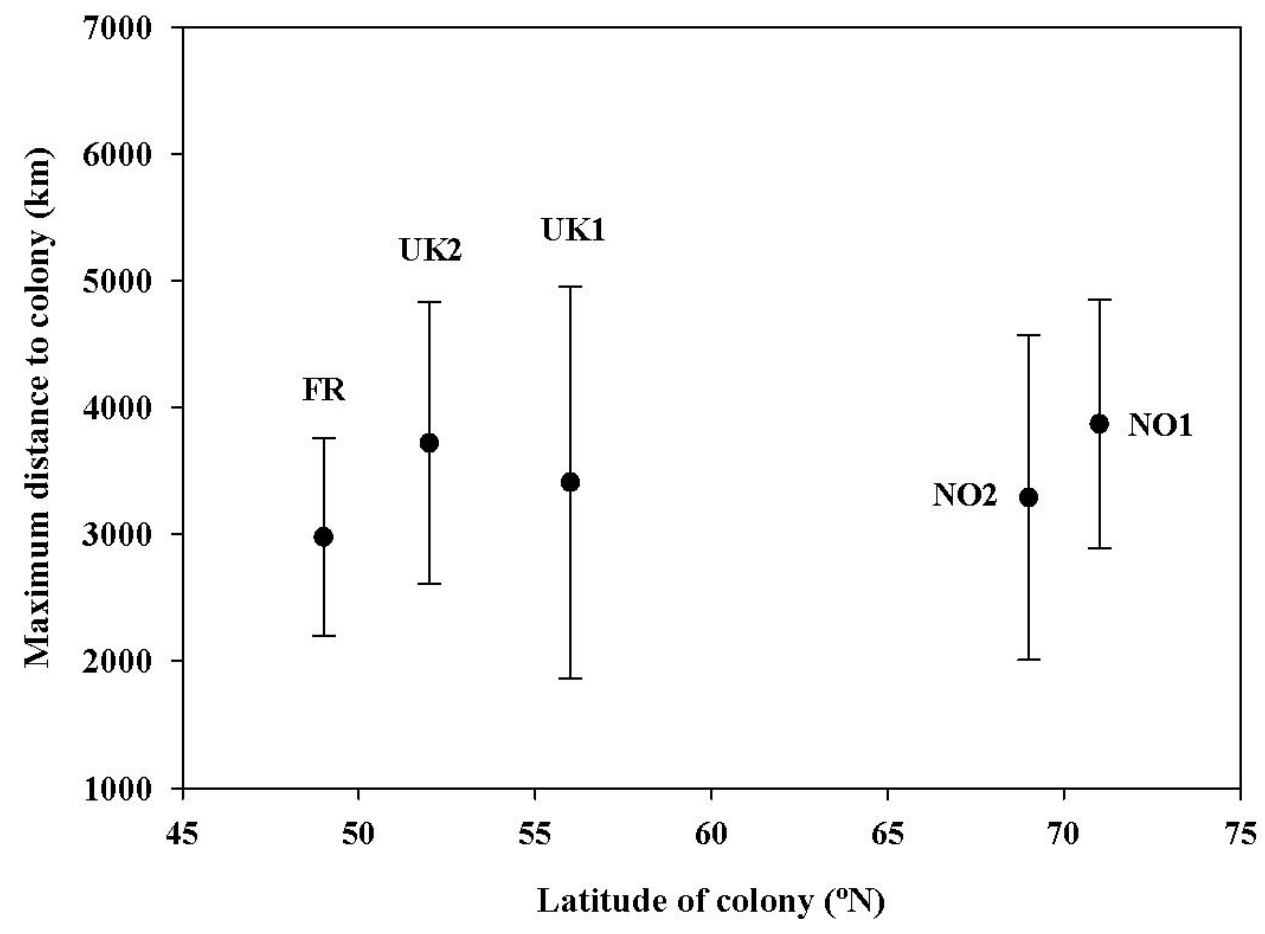

Figure 2. Maximum distance to the colony $(\mathrm{km})$ for each study colony. Values are means \pm s.d. 


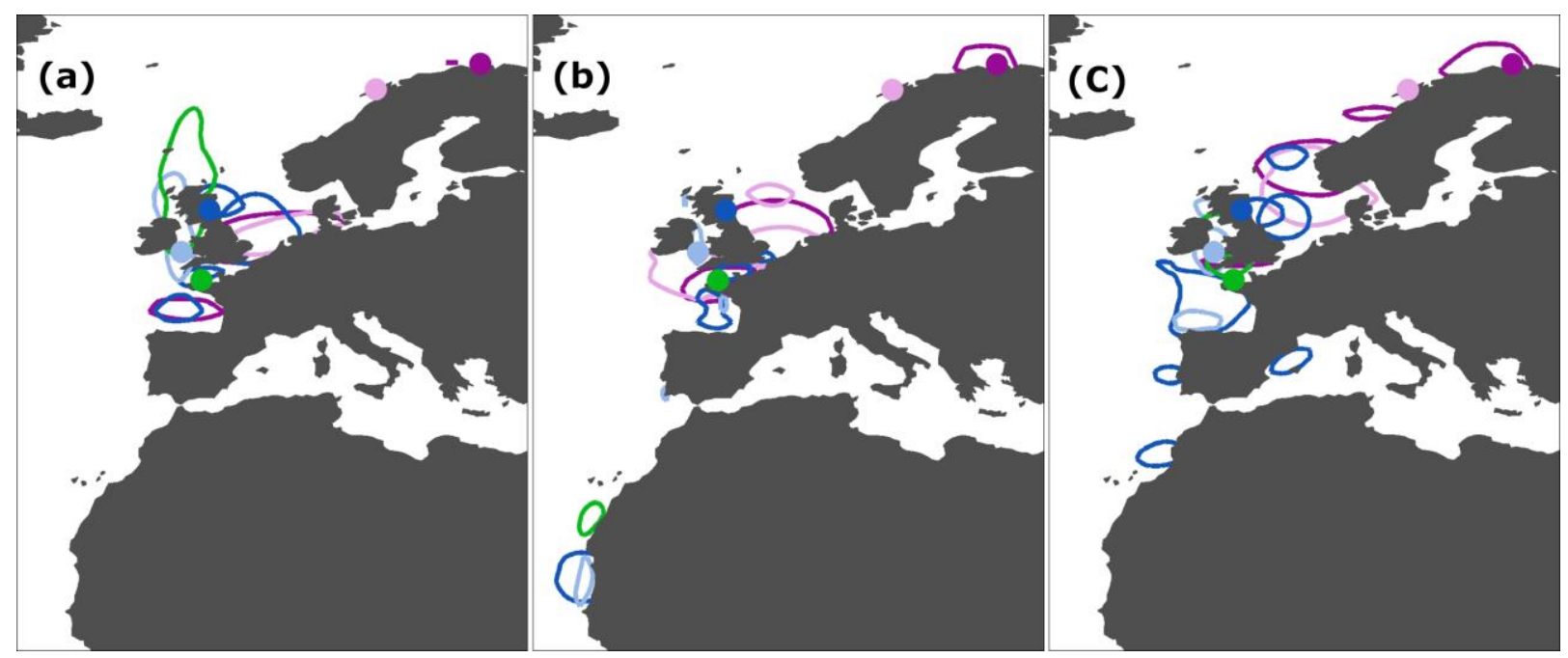

Figure 3. Main areas occupied by gannets during the non-breeding period, represented by $25 \%$ kernel density contours. (a) pre-winter (October) distribution, $(b)$ winter (December) distribution, $(c)$ post-winter (February) distribution. On each map, plain-colour dots represent the different breeding colonies (see Figure 1), a same colony-specific colour being associated with the kernel density contours. 